\title{
Pregabalin for perioperative anxiety: A re-audit of quality of recovery in ocular oncology patients
}

\section{Anaesthesia,audit, Surgery,ophthalmological, Recovery}

G. Sidaras1, A. Fyson1, A. Devindaran1, D. Sethuraman1, S. Swaraj1, H. Heimann2

1Department of Anaesthesia, Royal Liverpool University hospital, - Liverpool (United Kingdom),

2Department of Ophthalmology, Royal Liverpool University hospital, - Liverpool (United Kingdom)

\section{Background}

Our previous audit showed high levels of peri-operative anxiety which negatively impacted recovery in our cohort of 71 ocular melanoma patients undergoing surgical treatment ${ }^{1}$. Pregabalin already has an established role in the treatment of generalized anxiety and oculofacial pain ${ }^{2}$ and is routinely used in the perioperative period for joint replacement surgery and amputations in our hospital. Therefore, we introduced routine pregabalin in this cohort of ocular oncology patients and undertook a reaudit to evaluate improvements in their recovery.

\section{Method}

A small dose of $75 \mathrm{mg}$ Pregabalin BD for 10 days was routinely commenced from the day of surgery unless contraindicated. A single QoR-15 questionnaire ${ }^{3}$ was administered at $48 \mathrm{hrs}$ postop and the scores thus obtained was compared with our previous results ${ }^{1}$ using Mann-Whitney $U$ non parametric tests. 32 patients undergoing surgical treatment were prospectively audited over a 4 month period from Sept 2017 to Dec 2017 for this study.

\section{Results}

These are summarized in figure 1 . The mean QoR-15 scores improved from 126.3 (95\% Cl: $122.2 ; 130.4$ ) to 130.4 (95\%Cl: $124.6 ; 136.1)$. The scores improved for 9 areas with notable improvements in sleep, rest, food, pain, worry and feeling sad. Sleep and moderate pain were statistically better in the pregabalin cohort. There was a marginal decline in scores for work, hospital support \& comfort. The rest were similar to baseline.

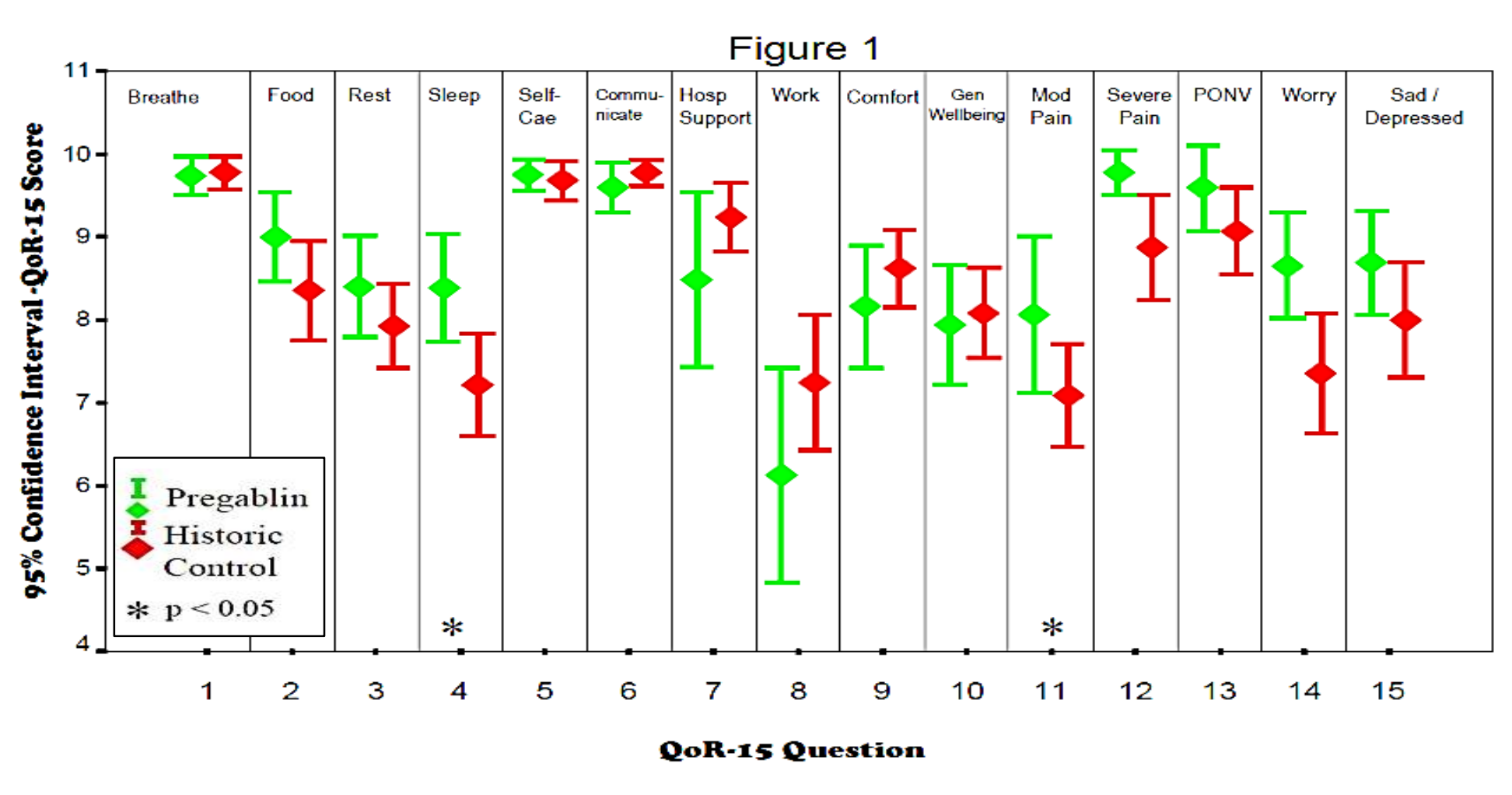

QoR-15questionnaire

PART A : How have you been feeling in the last 24 hrs? ( 0 to 10 , where: $0=$ none of the time [poor] and $10=$ all of the time [excellent])

\begin{tabular}{|c|c|c|}
\hline 1 & Able to breathe easily & \multirow{10}{*}{$\begin{array}{l}\text { None of the time --- All of } \\
\text { the time } \\
012345678910\end{array}$} \\
\hline 2 & Been able to enjoy food & \\
\hline 3 & Feeling rested & \\
\hline 4 & Have had a good sleep & \\
\hline 5 & $\begin{array}{l}\text { Able to look after personal toilet and } \\
\text { hygiene unaided }\end{array}$ & \\
\hline 6 & $\begin{array}{l}\text { Able to communicate with family or } \\
\text { friends }\end{array}$ & \\
\hline 7 & $\begin{array}{l}\text { Getting support from hospital doctors } \\
\text { and nurses }\end{array}$ & \\
\hline 8 & $\begin{array}{l}\text { Able to return to work or usual home } \\
\text { activities }\end{array}$ & \\
\hline 9 & Feeling Comfortable and in control & \\
\hline 10 & Having a feeling of general well-being & \\
\hline \multicolumn{3}{|c|}{ PART B : Have you had any of the following in the last $24 \mathrm{hrs}$ ? } \\
\hline & 0 , where: $10=$ none of the time [excellent] an & $0=$ all of the time [poor] $)$ \\
\hline 11 & Moderate pain & \multirow{5}{*}{$\begin{array}{l}\text { None of the time ---All } \\
\text { of the time } \\
109876543210\end{array}$} \\
\hline 12 & Severe Pain & \\
\hline 13 & Nausea and Vomiting & \\
\hline 14 & Feeling worried or anxious & \\
\hline 15 & Feeling sad or depressed & \\
\hline
\end{tabular}

\section{Discussion \& Conclusion}

Our results show that perioperative pregabalin improved pain, anxiety and sleep in patients undergoing ocular oncology procedures. It improved their overall quality of recovery as measured by QoR-15 scores. The obvious limitations of our methodology includes lack of randomization \& placebo control.

Therefore, we conclude that routine pregabalin use has a role in the perioperative management of ocular oncology patients.

References: 